No. 3

\title{
THERMAL STUDY OF THE PHASE TRANSITIONS IN POTASSIUM HYDROGEN SULPHATE $\mathrm{KHSO}_{4}$
}

\author{
K.K. TAIIOON ${ }^{a}$, A.M. ABosenLy ${ }^{a}$, M.M. ABDEL-KADER ${ }^{b}$, \\ A.A. EL-SIIARKAWYa AND F.M. EL-MANSI ${ }^{b}$ \\ a Physics Department, Faculty of Science, Al- zahar University, Nasr City Cairo, Egypt \\ ${ }^{b}$ Physics Department, Faculty of Science, Cairo University, Giza, Egypt
}

(Received June 22, 1993; revised version April 28, 1994)

We report on some thermal propertics (specific heat capacity $C_{\mathrm{p}}$, thermal conductivity $\lambda$, and thermal diffusivity $\sigma$ ) in addition to the differential thermal analysis thermogram and thermogravimetric analysis for potassium hydrogen sulplate (KIIS), $\mathrm{KISO}_{4}$. The accurate measurements of the above-mentioned parameters as functions of temperature revealed that the compound uudergoes two structural phase transitions around $100^{\circ} \mathrm{C}$ and $175^{\circ} \mathrm{C}$. It seems also likely that the compound behaves as a poorly conducting material and hence the main mechanism of the heat transfer is due to phonons. The data are correlated to the crystal structure including the two different $\mathrm{HSO}_{4}^{-}$ions.

PACS numbers: 64.70.-p, 65.10.-

\section{Introduction}

Potassium hydrogen sulphate (KIIS), $\mathrm{K}^{\prime} \mathrm{ISO}_{4}$, is a member of class of hydrogen sulphate family, $\mathrm{MISO}_{4}$, where $\mathrm{M}$ is a monovalent element or group $\left(\mathrm{M}^{+}=\mathrm{Na}^{+}, \mathrm{K}^{+}, \mathrm{Rb}^{+}, \mathrm{Cs}^{+}\right.$and/or $\left.\mathrm{NII}_{4}^{+}\right)$. This series of compounds has attracted the attention of investigators because of their interesting properties. For example, ammonium hydrogen sulphate, $\mathrm{NH}_{4} \mathrm{IISO}_{4}$, and rubidium hydrogen sulphate, $\mathrm{RbIISO}_{4}$, were found to be ferroclectric at low temperatures [1-2]. The crystal structures of some members of this series were determined [3-9]. The most interesting group in the crystal structurc of this scries is the $\mathrm{ISSO}_{4}^{-}$ion which is usually found to be distorted and arranged in a tetrahedral symmetry. Also the hydrogen sulphate ions, $\mathrm{ISO}_{4}^{-}$, are connected with short hydrogen bonds. The latter were found to be responsible for the plase transitions in these compounds [1-2]. Another point of interest is that the members of this family are not isomorphous: For example, the crystal structure of $\mathrm{CsHSO}_{4}$ [3] is not isomorphous with those of $\mathrm{NII}_{4} \mathrm{IISO}_{4}[4]$ and $\mathrm{Rb} \mathrm{IISO}_{4}[5]$ or with non-ferroelectric sodium hydrogen 
sulphate $\mathrm{NaIISO}_{4}[6]$ and $\mathrm{KIISO}_{4}[7-9$ ]. IIowever these compounds crystallize in orthorhombic or monoclinic systems [3-9].

The crystal structure of KIIS is of particular interest. The general feature of the structure that was first determined by Loopstra et al. [7] and refined by Cruickshank [8] on the basis of two-dimensional data, was further refined by Cotton et al. [9] on the basis of three-dimensional data. Accordingly, the compound crystallizes in an orthorhombic unit cell with $a=8.412, b=9.880$ and $c=18.957 \AA$ and space group $\mathrm{Pbca}$. There are two distinct $\mathrm{ISO}_{4}^{-}$ions in the asymmetric unit cell. These two $\mathrm{ISO}_{4}^{-}$ions are differently linked by hydrogen bonds. The oxygen atoms of the $S_{1}$ tetrahedra are linked by a double hydrogen bridge on both sides, forming a dimer $\left[\left(\mathrm{ISO}_{4}\right)^{-}\right]_{2}$ across a centre of symmetry, Fig. 1a. This type of hydrogen bonding is similar to that found in the carboxylic acid dimers. On the other hand the $S_{2}$ tetrahedra are linked by a bridge repeating through the glide plane [100], thus forming an infinite chain (polymer) [(IISO $\left.\left.{ }_{4}\right)^{-}\right]_{n}$ along the $a$-axis, Fig. 1b. This type of hydrogen bonding is similar to the one found in the other acid salts possessing phase transitions such as potassium dihydrogen phosphate (KDP) $\mathrm{KII}_{2} \mathrm{PO}_{4}[10-11]$. This interesting hydrogen bonding system is responsible for most of the physical propertics of this salt [12].
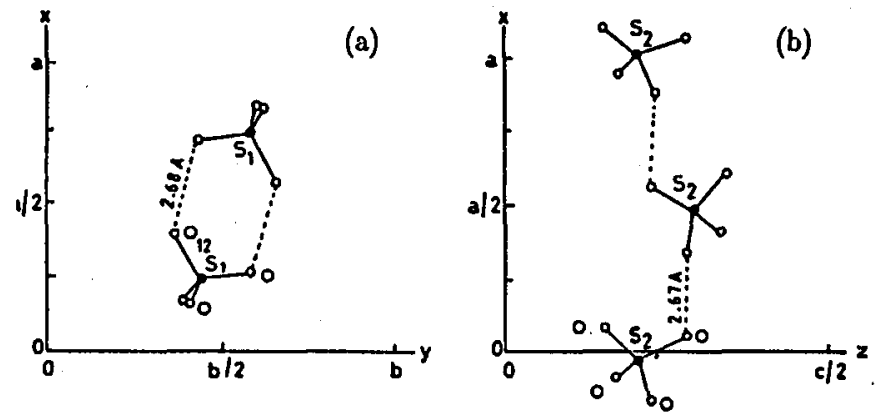

(c)

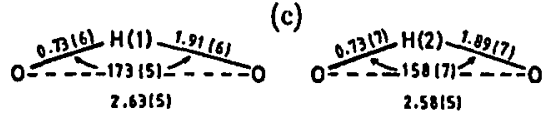

Fig. 1. IIydrogen bonding system; (a) dimer type (Ref. [7]), (b) infinite chain (polymer) type (Ref. [7]), (c) geometry of the lyydrogen bonding (Ref. [9]).

Previous investigators have reported on some physico-chemical properties of KIIS salt. For example, Rogers and Ubbelohde [13] measured the dc conductance of KIIS melt and the solid frozen from it to delermine the energy of activation for the conductance process. They observed two breaks (or discontinuities) in conductivity plot $\left(\sigma\right.$ vs. $T$ ) around $95^{\circ} \mathrm{C}$ and $170^{\circ} \mathrm{C}$. These two breaks are possibly due to the presence of some sort of phase transitions. The thermoelastic properties in the temperature range of $20-80^{\circ} \mathrm{C}$ of single crystals have been investigated by Gelrich and Siegert [12]. Their results indicated the absence of any pliase transitions in this short range of temperature. Bridgman [14] reported two transitions at about 
$164.2^{\circ} \mathrm{C}$ and $180^{\circ} \mathrm{C}$. According to Sharon and Kalia [15], KIISO ${ }_{4}$ is a pure protonic conductor and exlibits structural phase transitions in the vicinity of $170-180^{\circ} \mathrm{C}$. It appears that many of reported studies require a critical examination.

In a series of recent papers [16-18] we investigated the phase transitions in some organic and inorganic salts through the study of some of their electrical, thermal and/or calorimetric propertics. Selected examples are: ammonium purpurate [16], ammonium tartrate [17] and mercury (II) and ccrous (III) sulphates [18].

This paper deals with the study of calorimetric (thermal) properties such as thermal specific heat capacity $C_{\mathrm{p}}$, thicrmal conductivity $\lambda$ and thermal diffusivity $\sigma$, in addition to the differential thermal analysis (DTA) thermogram and the thermogravimetric analysis (TCA).

\section{Experiment:al}

The material used in the present work was manufactured by the British Drug IIouses Ltd (BDII). Recrystallization from water was carried out. For calorimetric measurements, the crystal were ground to very fine particles and compressed under a suitable pressure to form pellets. The diameter of each pellet is $\simeq 2 \mathrm{~cm}$ and its thickness $1.5-1.0 \mathrm{~mm}$.

The experimental technique is based on the so-called flash method. The theory of this method was discussed elsewhere $[16,19]$. The thermal diffusivity $\sigma$ can be calculated by the equation

$$
\sigma=0.139 \ell^{2} / \iota_{0.5}
$$

where $t_{0.5}$ is the time required for the lower surface of the sample to reach half maximum in its small temperature rise and $\ell$ is the sample thickness. The heat losses by radiation from the surfaces of the sample are minimized by performing the measurements in a very short time. 'The thermal specific heat capacity $C_{\mathrm{p}}$ can be determined by the relation

$$
C_{\mathrm{p}}=q / M T_{\mathrm{m}} \text {, }
$$

where $q$ - the energy dissipated through the sample,

$M$ - the mass of the sample,

$T_{\mathrm{m}}$ - the maximum temperature rise.

One can determine the power dissipated through the sample by using a standard material of known specific heat capacily. Again, the heat losses by radiation from the boundaries of each sample were considered. The thermal conductivity $\lambda$ is related to the specific heat capacity $C_{\mathrm{p}}$ and the diffusivity $\sigma$ by the equation

$$
\lambda=\mathcal{P} C_{\mathrm{p}} \sigma,
$$

where $\mathcal{P}$ is the density of a sample. The systematic error in $\sigma$ is better than $3 \%$, in $C_{\mathrm{p}}$ about $2 \%$ and in $\lambda c a .5 \%$.

The differential thermal analysis (DTA) was performed using IIeraeus TA 500 whereas the thermogravimetric analysis (TGA) was measured using a modern computerized system type Perkin-Elmer TG $\Lambda 7$ analyzer. 


\section{Results}

Figure 2 shows the variation of the specific heat capacity $C_{\mathrm{p}}$ with temperature $30^{\circ}<T<200^{\circ} \mathrm{C}$. It can be seen that the value of $C_{\mathrm{p}}$ is nearly temperature independent in the range $30^{\circ}<T<90^{\circ} \mathrm{C}$, however a further increase in temperature leads to a gradual increase in the value of $C_{\mathrm{p}}$ and hence a broad peak centred at about $100^{\circ} \mathrm{C}$ is obtained. This behaviour of $C_{\mathrm{p}}$ versus temperature $(T)$ may suggest a structural phase transition at about $100^{\circ} \mathrm{C}$. In the temperature range $110^{\circ} \mathrm{C}<T<160^{\circ} \mathrm{C}$, there is a slight increase in the values of $C_{\mathrm{p}}$ (from about $11 \times 10^{2} \mathrm{~J} \mathrm{kgm}^{-1} \mathrm{~K}^{-1}$ to about $\left.14 \times 10 \mathrm{~J} \mathrm{kgm}^{-1} \mathrm{~K}^{-1}\right)$. The value of $C_{\mathrm{p}}$ increases sharply as the temperature approaches $170^{\circ} \mathrm{C}$ reaching its maximum value at about $175^{\circ} \mathrm{C}$ and then decreases again. Such a change of $C_{\mathrm{p}}$ with temperature may also suggest a structural phase transition at about $175^{\circ} \mathrm{C}$.

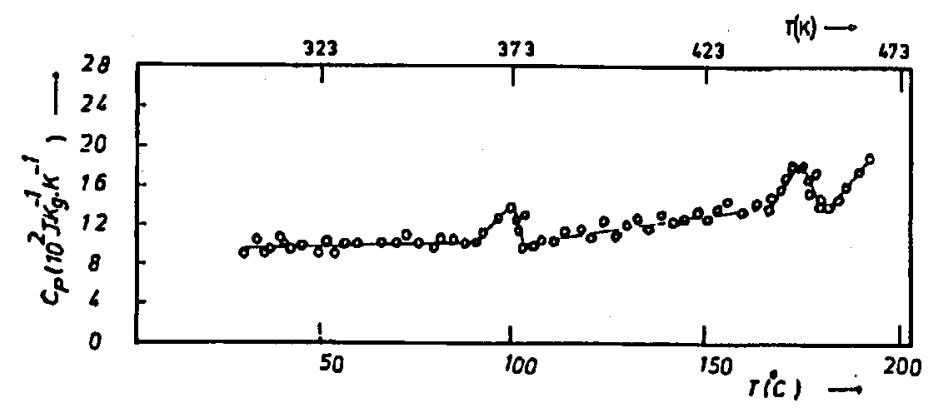

Fig. 2. Variation of the thermal specific heat capacity $\left(C_{\mathrm{p}}\right)$ with temperature $(T)$.

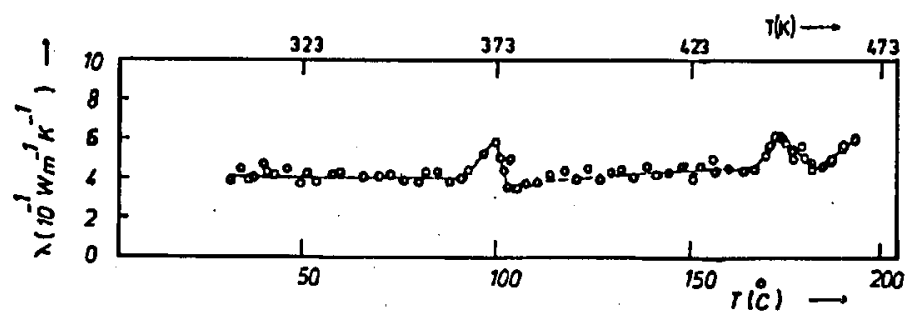

Fig. 3. Temperature dependence of the thermal conductivity $(\lambda)$.

The relationship between the thermal conductivity $\lambda$ and temperature in the same temperature range is shown in Fig. 3. The plot is characterized by the presence of two maxima at about $100^{\circ} \mathrm{C}$ and $175^{\circ} \mathrm{C}$. This behaviour of $\lambda$ versus $T$ is taken as an evidence for the existence of two transitions at the above-mentioned temperatures. Among other things, the order of magnitude of $\lambda$ suggests that the compound is a poorly conducting material. In Fig. 4 we have represented the 


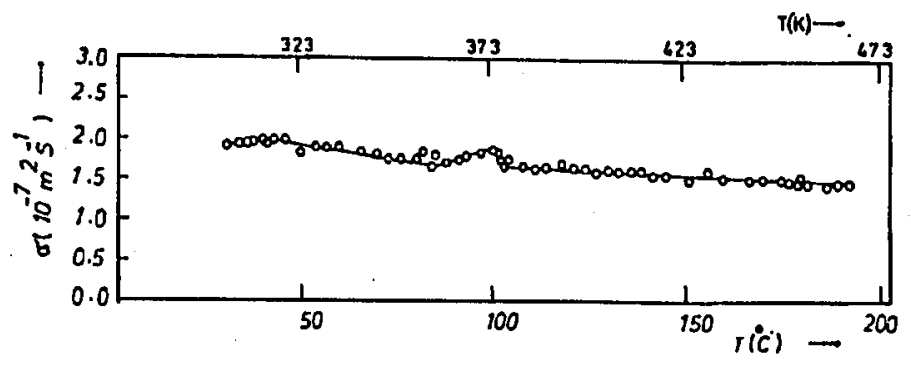

Fig. 4. Relationship between the thermal difusivity $(\sigma)$ and temperature $(T)$.

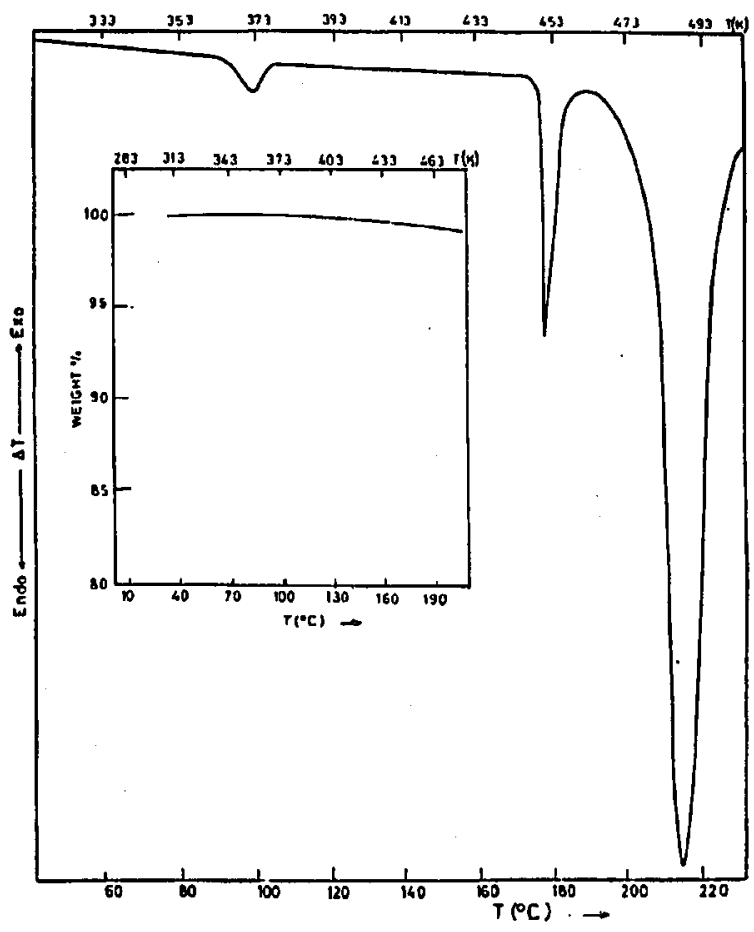

Fig. 5. The DTA thermogram. The inset: the TGA plot.

variation of thermal diffusivity $\sigma$ versus temperature. As a final confirmation of the observed phase transitions, we have performed the DTA thermogram from room temperature up to the melting point. The heating rate is $10^{\circ} \mathrm{C} / \mathrm{min}$. The thermogram resulting from such analysis is shown in Fig. 5 . As one can see, there are three endothcrmic peaks at $\approx 100^{\circ} \mathrm{C}, \approx 175^{\circ} \mathrm{C}$ and $\approx 215^{\circ} \mathrm{C}$, respectively. The first and the second peaks are due to the existence of the two structural phase transitions while the third peak is due to melting. 
The TGA plot is shown in the inset of Fig. 5 . The sample weiglit was $5.88 \mathrm{mg}$ and the scanning rate is $10 \mathrm{k} / \mathrm{min}$. The general feature of this plot is that there is no actual loss of weight between room temperature and $200^{\circ} \mathrm{C}$.

\section{Discussion}

The rneasured thermal parametcrs combined with the DTA thermogram clearly reveal that the compound undergoes two phase transitions around $100^{\circ} \mathrm{C}$ and $175^{\circ} \mathrm{C}$. Since the 'TGA plot (inset of Fig. 5) indicates the absence of any actual loss of weight between room temperature and $200^{\circ} \mathrm{C}$, i.e. in the transition temperature regions, the observed phase transitions are therefore of a structural origin.

As mentioned before [1-2], the change in the hydrogen bonding system is usually associated with phase transitions. For example, it is well known that the phase transition in ammonium sulphate $\left(\mathrm{NH}_{4}\right)_{2} \mathrm{SO}_{4}$ is not of the order-disorder type, but rather involves a change in the hydrogen bonding of ammonium ions to the sulphate ions [20]. This is also the case for ammonium purpurate [16]. On the same principle, one can find an interpretation of the structural phase transitions of the present compound. As mentioned above, the KIIS crystal has two types of hydrogen bonding scheme (a chain or polymer type as well as a dimer type). With increasing temperature, while approaching $100^{\circ} \mathrm{C}$, the thermal cnergy corresponding to this temperature is enough to brcak the chain type hydrogen bonding, since it is weaker than the dimer type. This is followed by the rotntion of the sulphate ion of $S_{2}$ tetrahedra to a proper oricntation which results in the observed structural phase transition around $100^{\circ} \mathrm{C}$. The break down of the strong hydrogen bonding (dimer type) requires higher thermal energy. Thus with increasing temperature gradually above $100^{\circ} \mathrm{C}$ and as we approach $175^{\circ} \mathrm{C}$ the thermal energy is large enough to either break down or at least change the dimer type into, for example, a chain type. This in turn causes the hydrogen sulphate ion of $S_{1}$ tetrahedra to rotate into another position. Such reorientational motion is associated with the observed phase transition at about $175^{\circ} \mathrm{C}$.

Another point of interest is the ligh value of the enthalpy $(1.21 \mathrm{eV})$ as obtained by Sharon et al. [15] in the high temperature region $\left(175^{\circ} \mathrm{C}\right)$. According to Sharon et al., this cnthalpy value $(1.21 \mathrm{eV})$ should include two terms, the enthalpy for the breakage of the liydrogen bond dimer, followed by the energy of rotation of the $\mathrm{ISO}_{4}^{-}$ion to the proper orientation to contribute to conduction [15].

Regarding the thermal properties of the investigated compound, the order of magnitude of $\lambda$ clearly indicates that it behaves as poorly conducting materials. The thermal conductivity $\lambda$ of such materials can be expressed by phononic and electronic modes of heat conduction, in other words,

$$
\lambda=\lambda_{\mathrm{ph}}+\lambda_{\mathrm{e}}
$$

where $\lambda_{\text {ph }}$ is the contribution of the lattice vibrations (phonons) to the total thermal conductivity $\lambda$ and $\lambda_{e}$ is the electronic part of the thermal conductivity. This part is negligible small for poor conducting materials and hence the above expression may be reduced to

$$
\lambda \approx \lambda_{\text {ph }} \text {. }
$$


Similarly, the specific heat capacity $C_{\mathrm{p}}$ is given

$$
C_{\mathrm{p}}=C_{\ell}+C_{\mathrm{e}}
$$

where $C_{\ell}$ is the specific heat capacity due to lattice vibrations (phonons). The electronic contribution to the total specific heat capacity is very small,

$$
C_{\mathrm{p}} \approx C_{\ell} \text {. }
$$

The conclusion, we could arrive at, is that this compound undergoes two structural phase transitions in the vicinity of $100^{\circ} \mathrm{C}$ and $175^{\circ} \mathrm{C}$. These two transitions are closely related to the onset of the rotational motion of the two distinct $\mathrm{IISO}_{4}^{-}$ions as a result of the change in the two hydrogen bonding schemes. Furthermore the compound behaves as a poorly conducting matcrial and therefore the mechanism of heat transport is duc to phonons.

\section{Roferences}

[1] R. Pepinsky, K. Vedam, K. Okaya, S. Itoshino, Phys. Rev. 111, 1508 (1958).

[2] R. Pepinsky, K. Vedian, Physs. Rcv. 117, 1502 (1960).

[3] R. Itolh, T. Ozaki, E. Nakiamura, Acta Crystallogr. B 37, 1908 (1981).

[4] R.J. Nelmes, Acta Cryslallogr. B 27, 272 (1971).

[5] J.P. Ashmore, II.E. Petch, Can J. Phys. 53, 2694 (1975).

[6] E.J. Sonncveld, J.W. Visser, Acta Crystallogr. B 34, 2694 (1978).

[7] L.II. Loopstra, C.II. MacGillavry, Acla Crystallogr. 11, 349 (1958).

[8] D.W.J. Cruickshank, Acta Crystallogr. 17, (682 (1964).

[9] F.II. Cotton, B.A. Frenz, D.L. IIunter, Acla Crystallogr, B 31, 302 (1975).

[10] S.R. Gough, J.A. Ripmester, N.S. Dalal, A.II. Reddoch, J. Plyys. Chem. 83, 664 (1979).

[11] J.E. Tibballs, R.J. Nelmes, G.J. McIntyre, J. Phys. C, Solid State Phys. 15, 37 (1982).

[12] D. Gerlich, II. Siegert, Acla Crystallogr. A 31, 207 (1975).

[13] S.E. Rogers, A.R. Ubbelolide, Trans. Faraday Soc. 46, 1051 (1950).

[14] P.W. Briclgman, Proc. Amcr. Acad. Arts. Sci. 52, 91 (1916/1917).

[15] M. Sharon, A.K. Kalia, J. Chem. Phys. 66, 3051 (1977).

[16] M.M. Abdel-Kader, K.K. Talıoon, A. El-Sharkawy, Plyss. Status Solidi A 135, 161 (1993).

[17] M.M. Abdel-Kader, F. El-Kabbany, S. Taha, A. Abousehly, K.K. Tahoon, A. El-Sharkawy, J. Phys. Chem. Solids 52, 655 (1991).

[18] M.M. Abdel-Kader, M.M. Mosad, S.A. Olola, M.I. Abdcl-Ati, A. El-Shawarby, Acta Phys. Pol. A 83, 187 (1993).

[19] W.J. Parker, R.J. Jenkings, C.P. Butcr, G.L Abott, J. App. Phys. 32, 1679 (1961).

[20] E.O. Echiemper, W.C. ITamilton, J. Chem. Phys. 44, 4498 (1966). 